\title{
TRENDS DEVELOPMENT IN DIGITALIZATION OF INTERNATIONAL BUSINESS
}

Karmaza O. O.

\section{INTRODUCTION}

The approach in this article is to review various sources about the potential adoption and impact of the new digital technologies (commonly known collectively as Industry 4.0), to contrast these technologies with existing technologies, and to consider how the new technologies might lead to new configurations involving suppliers, firms and customers. The new digital technologies have considerable potential to disrupt how and where activities are located and organized within GVCs), and who captures the value-added within those chains. Industry 4.0 is still in its infancy, but that its effects are already having an impact upon the nature of competition and corporate strategies in many industries.

Digitalization has been identified as one of the major trends changing society and business in the near and long term future ${ }^{1}$. The impact of digitalization will be major; it has been compared to the industrial revolution by several authors ${ }^{2,3,4,5}$. In this paper, digitalization is referred to as a more fundamental change than just digitizing existing processes or work products. The term digitization refers to "the action or process of digitizing; the conversion of analogue data (esp. in later use images, video, and text) into digital form". According to literature, digitalization, or digital transformation, refers to "the changes associated with the application of digital technology in all aspects of human society"6. Digitalization is

1 Tihinen M., Kääriäinen J. (eds.). The Industrial Internet in Finland: on route to success? Espoo, Finland: VTT, VTT Technology; 278. ISBN 978-951-38-8484-0, URL: http://www.vtt.fi/ inf/pdf/technology/2016/T278 .pdf, 2016.

2 Degryse C. Digitalisation of the economy and its impact on labor markets, Working paper 2016.02, Published by the European Trade Union Institute (ETUI), 2016.

3 The Economist. The third industrial revolution. 2012. URL: http://www.economist.com/ node $/ 21553017$.

4 Schwab K. The Fourth Industrial Revolution (Foreign Affairs). 2015, Dec, 12. URL: https://www.foreignaffairs.com/articles/2015-12-12/fourth-industrial-revolution.

5 Tihinen M., Iivari M., Ailisto H., Komi M., Kääriäinen J. and Peltomaa I. An exploratory method to clarify business potential in the context of industrial internet - a case study, in Collaboration in a Hyperconnected World, 17th IFIP WG 5.5 Working Conference on Virtual Enterprises, PRO-VE 2016, Hamideh, Afsarmanesh et al., eds. Springer, Porto, Portugal. 2016. Pp. 469-478.

6 Stolterman E., Fors A. Information Technology and the Good Life in Information Systems Research: Relevant Theory and Informed Practice / B. Kaplan et al. (eds), London, UK : Kluwer Academic Publishers, 2004. 
also known as the "ability to turn existing products or services into digital variants, and thus offer advantages over tangible product" $"{ }^{8}$. New research study on "Global digital transformation market" to show growth with a cagr of $13.4 \%$ to reach us $\$ 470.5$ million by 2024 , from us $\$ 250.4$ million in 2019 with its major key players during forecast period 2019-2024.

\section{Theoretical basis}

According to Brennen and Kreiss ${ }^{9}$ digitalization refers to "the adoption or increase in use of digital or computer technology by an organization, industry, country, etc. "Digital transformation is defined as changes in ways of working, roles, and business offering caused by adoption of digital technologies in an organization, or in the operation environment of the organization. This refers to changes at several levels, including the following:

Process level: adopting new digital tools and streamlining processes by reducing manual steps;

Organization level: offering new services and discarding obsolete practices and offering existing services in new ways;

Business domain level: changing roles and value chains in ecosystems;

Society level: changing society structures (e.g., type of work, means of influencing decision making).

The potential benefits of digitalization are high; already by digitizing information-intensive processes, costs can be cut by up to $90 \%$ and turnaround times improved by several orders of magnitude. In addition, replacing paper and manual processes with software allows businesses to automatically collect data that can be mined to better understand process performance, cost drivers, and causes of risk. Real-time reports and dashboards on digital-process performance permit managers to address problems before they become critical ${ }^{10}$. According to Sabbagh et al. ${ }^{11}$

7 Gassmann O., Frankenberger K. and Csik M. The St. Gallen Business Model Navigator. 2014. URL: http://www.im.ethz.ch/education/HS13/MIS13/Business_Model_Navigator.pdf.

8 Henriette E., Mondher F. and Boughzala I. The Shape of Digital Transformation: A Systematic Literature Review, in Ninth Mediterranean Conference on Information Systems (MCIS), Samos, Greece, 2015.

9 Brennen S. and Kreiss D. Digitalization and Digitization. 2014. URL: http://culturedigitally. org/2014/09/digitalization-and-digitization/.

10 Markovitch S. and Willmott P. Accelerating the digitization of business processes. White paper, McKinsey \& Company. 2014. URL: http://www.mckinsey.com/insights/business technology/accelerating_the_digitization_of_business_processes.

11 Sabbagh K., Friedrich R., El-Darwiche B., Singh M., Ganediwalla S. and Katz R. Maximizing the impact of digitization (Strategy\&). Previously published in the Global Information Technology Report 2012: Living in a Hyperconnected World, pwc, pp. 68-73, 2012. URL: http:// www.strategyand.pwc.com/media/file/Strategyand_Maximizing-the-Impact-of-Digitization.pdf. 
digitalization offers incremental economic growth; countries at the most advanced stage of digitalization derive $20 \%$ more in economic benefits than those at the initial stage. Digitalization has a proven impact on reducing unemployment, improving quality of life, and boosting citizen access to public services. Finally, digitalization allows governments to operate with greater transparency and efficiency.

Even though the importance of digitalization is well known, companies are often struggling to understand the potential impact and benefits of digitalization. In practice, there are many obstacles to digital transformation. According to Henriette et al. ${ }^{12}$, a digital transformation project involves implementing digital capabilities to support business model transformations impacting entire organizations, especially operational processes, resources, internal and external users.

Mature companies typically had a clear digital strategy combined with a collaborative culture and leadership that was driving the transformation and encouraged risk taking. However, in many companies, failed implementation of enterprise resource planning was common, many times due to previous generations' knowledge management systems. The transformation did not succeed because organizations did not change mindsets and processes or build a culture that could foster the change. Lack of an overall digitalization strategy and competing priorities were the most typical obstacles for digitalization, together with security concerns and insufficient technical skills.

Digitalization affects many aspects of organizations, including information technology, strategy and business models, products and services, internal and external processes, organization and company culture, etc.

As pointed out, digitalization is already impacting business environments and the corporate way of working. Neglecting digitalization could create a risk of losing the game in the highly competitive markets. Digitalization can impact a company's entire operation environment and internal functioning. Digitalization can also bring new business opportunities, change the roles of operators in a value chain, and end existing business. For example, digitalization may remove traditional intermediates in the supply chain and create new intermediates. This can be due to, for example, direct access to consumers and the increased use of mobile devices.

Thus, the impact of digitalization, and the goals of digitalization for an organization, can be identified from three different viewpoints:

\footnotetext{
12 Henriette E., Mondher F. and Boughzala I. The Shape of Digital Transformation: A Systematic Literature Review, in Ninth Mediterranean Conference on Information Systems (MCIS), Samos, Greece, 2015.
} 
1. Internal efficiency; i.e., improved way of working via digital means and re-planning internal processes.

2. External opportunities, i.e., new business opportunities in existing business domain (new services, new customers etc.).

3. Disruptive change; digitalization causes changes business roles completely.

The potential benefits of digitalization for internal efficiency include improved business process efficiency, quality, and consistency via eliminating manual steps and gaining better accuracy. Digitalization can also enable a better real time view on operation and results, by integrating structured and unstructured data, providing better views on organization data, and integrating data from other sources. Furthermore, digitalization can lead to better work satisfaction for employees through automation of routine work, thus freeing time to develop new skills. Digitalization also improves compliance via standardization of records and improves recovery via easier backups and distribution of storage.

External opportunities include improved response time and client service, as well as possibilities for new ways of doing business. New digital technologies can create opportunities for new services or advanced offerings to customers.

Disruptive changes involve changes in the operating environment of the company caused by digitalization; for example, a company's current business may become obsolete in the changed situation (e.g., manual scanning of invoices replaced by electronic invoice). On the other hand, digitalization can create completely new business, such as inclusion of an e-invoice operator, for example.

The current trends of digitalization change the environment where companies operate. The changes can be new possibilities to do things more effectively or affordably, but they can also be disturbing to a company's current operations, as digitalization fundamentally changed a company's business opportunities. Digitalization is not about turning existing processes into digital versions, but rethinking current operations from new perspectives enabled by digital technology. Well-known examples of digital transformation include Über disturbing taxi business, Airbnb disturbing hotel business, and streaming of music and movies disturbing record company, cable television, or movie network business.

Digitalization affects all businesses, and the impact will only increase in the future. Therefore, it is important that companies take a proactive approach, rather than waiting to see what will happen or thinking that 
their current position in the markets will remain the same if they do not do anything.

Digitalization is the key enabling issue for providing internal efficiency in organizations, or for providing external opportunities such as new services or offerings to customers. In addition, there can be disruptive changes in the operating environment of the company caused by digitalization. All of these changes can be translated into success even though digital transformation is a monumental and multi-dimensional concept. Each company's situation is different. Thus, there is no silver bullet for tackling digitalization.

Industry $4.0^{13}$ is a term reputedly first used to describe a high-technology strategy proposed by the German government, and is now commonly used to refer to the development of "cyber-physical systems (CPS) and dynamic data processes that use massive amounts of data to drive smart machines". Industry 4.0 is considered to be the fourth industrial revolution, following mechanization (the first revolution) in the nineteenth century, the intensive use of electrical energy for mass production (the second revolution) in the early part of the twentieth century and widespread digitalization (the third revolution) in the 1970s (Lasi et al., 2014).

For the past few decades, the scramble for competitive advantage in manufacturing has largely revolved around finding new and abundant sources of low-cost labor. But with wages rising rapidly in China and other emerging markets, manufacturers worldwide are under intensifying pressure to gain advantage the old-fashioned way - by improving their productivity.

Technological development is likely to be the catalyst for the next wave of manufacturing productivity gains. This development, which some refer to as Industry 4.0, is characterized by cyber-physical systems (CPS) and dynamic data processes that use massive amounts of data to drive smart machines. A confluence of forces-falling prices and rising performance of enabling hardware and software, the digitization of industry, increasing connectivity, and mounting pressure on manufacturers to be more flexible and eco-friendly-is likely to accelerate adoption of the next generation of advanced manufacturing technologies. In the near future, they may transform the economics of global production in many industries.

The term "advanced manufacturing" has been around for decades and means many things to many people. The Boston Consulting Group defines advanced-manufacturing technologies as a set of highly flexible,

13 Afuah A. Dynamic boundaries of the firm: are firms better off being vertically integrated in the face of a technological change? Academy of Management Journal, 2001, Vol. 44. No. 6, pp. 1211-1228. 
data-enabled, and cost-efficient manufacturing processes. These tools offer a range of benefits that, taken together, could redefine the economics of global-manufacturing competitiveness in a number of industries. In fact, leading-edge manufacturers, such as Ford and General Electric, are already using some of the most advanced tools to make high-precision components.

A large majority of American-based manufacturing executives are beginning to explore advanced manufacturing. In our third annual survey of U.S.-based manufacturing executives at companies with sales of at least $\$ 1$ billion, 72 percent of respondents said that they will invest in additional automation or advanced-manufacturing technologies in the next five years. Only 10 percent said that they are unlikely to do so. Roughly three quarters of the executives we surveyed said that they expect advanced manufacturing to improve productivity and create more localized production. Fifty-six percent of respondents predicted that lower automation costs will improve their competitiveness against products made in low-cost countries.

Advanced-manufacturing technologies can boost productivity in a number of ways. They dramatically increase flexibility by making it feasible for manufacturers in some industries to offer customers the option to "have it your way". Manufacturers can also make products in small batches for specific customers, adjust production lines in response to design changes, and even speed time to market by generating prototypes very quickly.

Advanced-manufacturing technologies can boost innovation, too, by allowing manufacturers to create new kinds of products that can't be made cost effectively with conventional processes. They also permit manufacturers to produce high-quality goods made to buyers' exact specifications. What's more, these processes are good for the environment because they often consume fewer raw materials and generate less scrap. They improve safety as well, by exposing workers to fewer hazardous materials.

As of now, BCG believes that the following five technological tools have the greatest potential to influence the manufacturing landscape and improve productivity in the years ahead.

- Autonomous Robots. A new generation of automation systems links industrial robots with control systems through information technology. New robotic and automation systems equipped with sensors and standardized interfaces are beginning to complement and, in some cases, eliminate human labor in many processes. This could enable manufacturers to costeffectively produce items at smaller scale and to improve their ability to enhance quality ${ }^{14}$.

\footnotetext{
14 The Rise of Robotics. BCG article, August 2014.
} 
- Integrated Computational Materials Engineering(ICME). By creating computer models of products and simulating their properties before they are fabricated - rather than building and testing multiple physical prototypes engineers and designers can develop products better, faster, and cheaper.

- Digital Manufacturing. Virtualization technology can be used to generate complete digital factories that simulate the entire production process. Among other things, digital simulation can help engineers save time and money by optimizing the layout of a factory, identifying and automatically correcting flaws in each step of the production process, and modeling product quality and output. Entire assembly lines can be replicated in different locations at relatively low cost.

- The Industrial Internet and Flexible Automation. Manufacturing hardware can be linked together so that machines are able to communicate with one another and automatically adjust production based on data generated by sensors. They can "see" into the supply chain.

- Additive Manufacturing. Commonly known as 3-D printing, additive manufacturing processes create three-dimensional objects based on digital models by successively depositing thin layers of materials. Such processes are already starting to be used for making prototypes in some industries, including aerospace, automotive parts, and basic consumer items. In the future, these processes are expected to be used to build small batches of new kinds of products made out of one solid piece of material, such as hollow spheres that have no seams ${ }^{15}$.

These technologies are not widely deployed today and won't have a significant impact in the very short term. They are also unlikely to replace labor as the most important cost factor in many industries over the next five to ten years. The material science of 3-D printing is still evolving, for example, with significant advances required to make it viable and cost effective for many substrates and particularly for end-use parts. But, to varying degrees, each of these advanced-manufacturing tools is already being used by leading-edge manufacturers with impressive results. And they are expected to eventually become important factors in industry.

While predictions of a new technological leap in manufacturing have been circulating for quite some time, the move is now getting closer to reality for several reasons. One is a trend that BCG has been following for the past three years: the shifting economics of global manufacturing ${ }^{16}$.

\footnotetext{
15 Prepare for Impact: 3-D Printing Will Change the Game. BCG article, September 2013.

16 The Shifting Economics of Global Manufacturing: How Cost Competitiveness Is Changing. World-wide, $B C G$ report, August 2014.
} 
For example, when Chinese labor costs were around one-twentieth of those in the U.S. a little more than a decade ago, it was a no-brainer to locate production in China rather than invest in expensive state-of-the-art capacity in the U.S. Today - after accounting for productivity, logistics, and other costs - the cost gap between China and the U.S. has nearly disappeared for many products. Similarly, several Eastern European economies have lost much of their cost competitiveness compared with the UK, and Brazil is now estimated to be more expensive than much of Western Europe ${ }^{17}$.

A number of other trends are also having an impact. Rapid advances in information technology, sensors, and nonmaterial's are dramatically lowering the costs of leading-edge manufacturing processes and improving their performance. Slowly but surely, digitization has begun to permeate every aspect of the production process, from engineering to management of the supply chain to the factory floor-making production systems more intelligent and highly networked. At the same time, companies are under mounting pressure to improve their productivity and become more responsive to shifting customer needs.

Advanced-manufacturing technologies could potentially help address a number of these needs. New processes boost productivity and responsiveness to the market by making it possible for manufacturers to quickly and easily modify designs and re-configure production lines according to customer demands. As a result, manufacturers can generate a greater diversity of products using a similar set of processes. Factories of the future will combine the efficiency of mass production with custom manufacturing: each machine will be capable of producing a variety of bespoke goods that are made specifically for the needs of customers something that is difficult and often prohibitively expensive, to do using conventional manufacturing processes. They could even make one-off objects without additional capital expenditures.

Because information technology can enable networks of robots to communicate with one another, entire production systems and supply chains can also become more efficient. Robots can relay data on a problem in one part of a production line to robots in other parts of the line, so they can adjust. Furthermore, by accessing supplier networks through the Industrial Internet, robots can automatically adjust production flows in line with updated delivery schedules for parts and materials, thereby reducing waste and inventory costs.

${ }_{17}$ Made in America, Again: Why Manufacturing Will Return to the U.S., $B C G$ Focus, August 2011. 
Several leading manufacturers are already demonstrating the potential of some of these advanced processes. Ford Motor, for example, is using ICME to reduce the time and cost of developing aluminum castings for engines. The conventional method is to design an engine block on a computer, build a physical prototype, test it, and then tweak the design, rebuild the prototype, and retest it - again and again - until the product is ready to be manufactured. Using an ICME process, digital models of castings are tested virtually, and a prototype is built only after engineers are convinced that they have created the best design. Ford invested $\$ 15$ million over five years in this ICME experiment, which involved 15 of its own engineers and 10 university researchers. So far, the company estimates that it has generated cost savings of more than $\$ 120$ million - a $700 \%$ return on investment - while development times have been cut by 15 to $25 \%$.

General Electric is successfully using additive-manufacturing processes to build fuel nozzles for LEAP turbofan engines, which are being developed for next-generation single-aisle aircraft. In the additive-manufacturing process, the nozzles are built by a computer-guided laser from layers of metal powder. "The new nozzle is 25 percent lighter than the machined component and is as much as five times more durable than the current nozzle made from 20 different parts", GE reports. According to a company press release, GE will spend $\$ 32$ million to build a new research-and-education center focused on additive technologies in Pennsylvania.

BCG believes that as advanced manufacturing processes improve, become more practical, and are disseminated through the supply chain, many more manufacturers will realize significant gains in cost and productivity. According to analysis by $\mathrm{BCG}$, a combination of these tools could help reduce production costs (excluding raw materials) by 20 to $40 \%$.

The next technological revolution in manufacturing will take time to fully unfold, but the early stages have already begun. Over the next year, we at BCG will begin to share with you our in-depth perspectives on several of these technologies and explore their probable impact on manufacturing industries.

Manufacturers reassessing their global production networks in light of dramatic shifts in costs such as labor and energy must embrace advancedmanufacturing technologies. It is too early to grasp the comprehensive impact of these tools and processes or to see how they will evolve. But it is clear that they will radically redefine the dynamics of global competition in many industries. Advanced-manufacturing technologies will enable companies to manufacture goods faster, better, and cheaper and lead to quantum leaps in productivity. 
To sum up, Industry 4.0 refers to the emergence and diffusion of a range of new digital industrial technologies, notably embedded sensors, so that smart products and devices can communicate and interact with each other (the Internet of things or IoT); the collection and real-time evaluation of data to optimize the costs and quality of production (big data and analytics or BDA); robots with greater autonomy and flexibility; and advanced manufacturing techniques, such as additive manufacturing (3-D printing) ${ }^{18}$. Rü $\beta$ mann et al. (2015) list nine foundational technologies (i.e. big data and analytics; autonomous robots; simulation; horizontal and vertical system integration; the Internet of things; cybersecurity; the cloud; additive manufacturing; and augmented reality) that are the building blocks of Industry 4.0, but we concentrate here on just these four technologies because they are likely to have the most influence of firms' international business activities. Many of these digital technologies have been available for some time, but recent cost reductions and improvements in reliability mean that their deployment for industrial applications is now more commercially viable, although it is likely that this deployment may well take 15-20 years to be fully realized. Some technologies are not yet ready for application at scale.

One kind of lost value that is sure to interest manufacturers is process effectiveness. Industry 4.0 offers new tools for smarter energy consumption, greater information storage in products and pallets (so-called intelligent lots), and real-time yield optimization. Swiss giant $\mathrm{ABB}$ used the latter in an Australian cement kiln. A computer-based system mimics the actions of an "ideal" operator, using real-time metrics to adjust kiln feed, fuel flow, and fan-damper position. The company found that the new tools boosted throughput by up to $5 \%$. Potentially, Industry 4.0 may bring about a change from isolated manufacturing activities to automated, optimized and fully integrated product and data flows within (global) value chains.

Traditional manufacturing processes are subtractive in that parts and components are fabricated using machining techniques, which mostly rely on the removal of material by methods such as cutting, drilling, grinding and sanding. The final products then require assembly of the parts and components. In contrast, 3-D printing (Additive manufacturing is the official term, but the technology is often referred to as 3-D printing and also as direct digital manufacturing (DDM)) is an additive process that creates products by building up successive layers of materials, thus circumventing the need for component assembly (De Jong and Bruijn, 2013;

${ }_{18}$ Albertoni F., Elia S., Fratocchi L. and Piscitello L. Returning from offshore: what do we know?, AIB Insights, 2015. Vol. 15. No. 4, pp. 9-12. 
Janssen et al., 2014). A digital model is first generated using computer-aided design (CAD) software, and is then printed as a three-dimensional object in a 3-D printer from raw materials in either liquid or particle form. The printer deposits microscopically thin layers of the raw material, and the product gradually materializes as successive layers are deposited. Many different raw materials may be used as feedstock for 3-D printing, including metals, ceramics, plastics, synthetic resins, porcelain and glass (See also the May 2015 Technology Quarterly on "New materials in manufacturing" in The Economist (2015). Some 3-D printers can combine various materials together in one final product, whilst others can print moving parts.

The adoption of additive manufacturing technologies potentially brings a number of advantages (Janssen et al., 2014; Sasson and Johnson, 2016; Laplume et al., 2016). First, standard CAD software can be used by anyone (with the necessary skills) anywhere in the world to design products, and then to manufacture them using a suitable 3-D printer. Second, every product may be customized to meet the end-user's requirements, as 3-D printing allows for cost-effective production of very small batches - something that is not possible with traditional manufacturing processes. Third, 3-D allows the relatively easy production of complex products, and may well reduce overall production time as several manufacturing/assembly steps are consolidated. Fourth, traditional manufacturing processes generate considerable waste, whilst products often contain surplus material that is not feasible/economic to remove. In contrast, additive manufacturing generates little or no waste, and the design may be optimized so that products use less material and are thus lighter and/or stronger. And, in principle, many additive processes can be reversed, thus dissolving final products into raw material solutions that can be re-used. Finally - and particularly important in an international business context - products designed by CAD software can in principle be manufactured anywhere in the world where there is a compatible 3-D printer. Manufacturing does not need to be centralized but may be undertaken close to the end-users, with consequent savings in delivery times and transportation costs and reduced international flows of intermediate goods and services. Most raw materials are readily available from multiple suppliers and in most countries, hence supply chain risk is minimized. In short, GVCs may be considerably simplified in terms of the number of distinct activities, their geographical dispersion, and the relationships between independent participants.

Unlike machining processes, which are subtractive in nature, 3-D printing systems join together raw materials to form an object. Drawing on 
a computer-aided design (CAD) file, the design for an object is first divided into paper-thin, cross-sectional slices, which are then each "printed" out of liquid, powder, plastic or metal materials in sequence until the entire object is created. The use of 3-D printing makes it possible to build physical models, prototypes, patterns, tooling components or production parts. Design and manufacturing organizations use it for product parts in the consumer, industrial, medical and military markets. The longer-term implications of 3-D printing technologies are believed to be large.

Direct advantages include enabling designers to operate more efficiently and conveniently. They can quickly prototype their designs in order to test their viability or demonstrate them. In addition, 3-D printing is increasingly used to manufacture products or parts in small batches that would be too costly for a traditional production line.

Industry 4.0 is still in its infancy, and the widespread deployment of many of its constituent technologies is still some years away. But its effects are already having an impact upon the nature of competition and corporate strategies in many industries (Rüßmann et al., 2015; Lorenz et al., 2016; Rose et al., 2016) report that cross-border data flows are increasing at rates that are almost 50 times those of the past decade, during a time when traditional globalization metrics (trade and FDI flows) are slowing. And, as Kietzmann et al. (2015, p. 214) comment in the context of additive manufacturing, "As with most disruptive technologies, it is likely that we will overestimate the potential of 3-D printing in the short term while underestimating it in the long term".

\section{Results}

Technological advances change the resource equation in a variety of ways:

- Advances in analytics, automation, and the Internet of Things, along with innovations in areas such as materials science, are already showing great promise at reducing resource consumption. Cement-grinding plants can cut energy consumption by 5 percent or more with customized controls that predict peak demand. Algorithms that optimize robotic movements can reduce a manufacturing plant's energy consumption by as much as 30 percent. And smart lighting and intuitive thermostats are significantly reducing electricity consumption in businesses as well as homes.

- Technology is transforming resource production. Gas and oil output has increased significantly because of advances in fracking, deepwater drilling, and enhanced oil recovery. Seawater desalination currently 
contributes hundreds of millions of cubic meters per year to Israel's water supply (up from less than 50 million in 2005), and the country now gets 55 percent of its domestic water from desalination.

- Technologies are combining in new ways, with the potential to reduce resource intensity dramatically. Vehicle electrification, ride sharing, driverless cars, vehicle-to-vehicle communications, and the use of new materials are rapidly coming together to reduce automobile weight, change driving patterns, and improve the utilization of cars and of road capacity. In fact, analysis by our colleagues suggests that global demand for oil could flatten by around 2025 under plausible scenarios regarding the adoption of light-vehicle technologies and slowing plastics consumption.

Technology isn't a panacea, of course; technological solutions come with external consequences. Fertilizers, for example, helped trigger a boom in agriculture, but fertilizer runoff polluted many water supplies. Fossil fuels lifted the standard of living for billions of people but have led to deteriorating air quality, oil spills, and carbon dangers that are ecologically existential and drivers of investment to meet regulations and arrangements (such as the Paris Agreement) aimed at slowing the impact of climate change.

But there is also opportunity. While companies are working through the implications of resource constraints for their business models, they will generate new ideas - creating less resource-intensive processes, turning waste into raw materials, and building a more circular economy. We can expect an accelerating resource-innovation cycle: growth will strain supplies, technology will yield solutions, externalities will arise, and further ideas will emerge in response.

As technology continues to progress and data flows reveal efficiency opportunities across operations, companies should have more influence over their cost structure, and resource prices should be less correlated to one another and to macroeconomic growth than they were in the past. McKinsey research suggests, for example, that iron-ore demand could decline over the next two decades as a result of softening demand for steel and increased recycling, but copper demand could jump, given its role in a wide range of electronics and consumer goods. Resource-related business opportunities will turn up in unexpected places, and there's room for a multitude of new products and services. An example is new carbon-based materials that are lighter, cheaper, and conduct electricity with limited heat loss. They could transform entire industries, including automobiles, aviation, and electronics.

Business leaders will have more opportunities to seize the initiative as they stretch their thinking about the changing nature of resource constraints. 
"Disruption" isn't just one of the most overused words in management writing; it's also one of the most imprecisely used. When we say industry disruption is accelerating, we mean that in many sectors, critical foundations of industry structure - the economic fundamentals, the power balance between buyers and sellers, the role of assets, the types of competitors, even the borders of industries - are rapidly shifting. While that degree of change can be uncomfortable or even destructive, it can also contain the seeds of opportunity.

Digitization highlights both sides of the coin. By reducing economic friction, digitization is enabling competition that pressures revenue and profit growth. It also is creating fresh opportunities to improve performance through supply-chain, product, process, and service improvements. Ensuring alignment between a companys' digital and its corporate strategy appears to be one of the factors differentiating winners and losers a useful reminder that leading today requires tough choices about big, disruptive forces.

The most radical technological advances have not come from linear improvements within a single subject or expertise, but from the combination of seemingly disparate inventions and disciplines. As W. Brian Arthur has noted, "The overall collection of technologies bootstraps itself upward from the few to the many and from the simple to the complex".

For example, consider how increased online connectivity, cryptography, and advanced analytics have combined to create a distributed, global database for transactions called blockchain. It's potentially a game changer, because transaction costs represent a substantial share of the world's commercial costs. In fact, the desire to avoid transaction costs such as the negotiating and writing of contracts helps explain why firms exist, according to Nobel laureate Ronald Coase. Since blockchains can process transactions without intermediaries, their potential impact on costs and competition is profound.

Business model innovation has seen a recent surge in academic research and business practice. Changes to business models are recognized as a fundamental approach to realize innovations for sustainability. However, little is known about the successful adoption of sustainable business models (SBMs). A unified theoretical perspective is still being developed for understanding business model innovations that lead to better organizational economic, environmental and social performance.

I identify two fundamental issues that firms face when trying to assess the impact of SBMs. On the one hand, there is a lack of a clear measurement system for the economic, environmental and social value creation potential of SBMs. On the other hand, the assessment involves multiple stakeholders with different stakes, goals and value creation abilities in the business 
model. How this assessment is performed in a meaningful manner presents a challenging task for practitioners and researchers in the field of SBMs.

Customers will become more involved in GVCs, as providers of key information and feedback on products, and even as local manufacturers. Relationships between firms and customers will be redefined in many ways as BDA allows the possibility to test, in advance, new products and services on clients located anywhere in the world, and to increasingly customize the firm offer to reduce development, launch and adaptation costs. The standardization versus adaptation decision - for long a key issue in international marketing theory and practice - will require a comprehensive re-evaluation in the light of this customization.

Growing interconnectivity of machines, products, parts, and humans will also require new internationals standards that define the interaction of these elements in the digital factory of the future. Efforts to develop these standards are in their infancy but are being driven by traditional standardization bodies and emerging consortia. Germany's Platform Industry 4.0 was the first driver, but the US-based Industrial Internet Consortium (IIC) - founded in March 2014 by manufacturing, Internet, IT, and telecommunications companies - has become a prominent alternative. Subsequently, a new body, the Dialog platform Industry 4.0, was formed in Germany to counteract the IIC's strong position. Several other standardization organizations have ambitions in the field.

\section{Analysis of development of digitalization in Ukraine}

Ukraine has long become a European leader in IT outsourcing, easily surpassing the reputation of Russia and Romania, despite the volatile political situation, thereby drawing even more attention from the global IT industry.

Exports of IT products and services in Ukraine are growing at a rapid pace.

Export of IT industry in 2015-2025

Table 1

Export volumes of IT products and services in Ukraine

\begin{tabular}{|c|c|}
\hline Year & Export of IT industry (billion, USD) \\
\hline 2015 & 3.9 \\
\hline 2016 & 3.2 \\
\hline 2017 & 3.6 \\
\hline 2018 & 4.5 \\
\hline 2020 (prognosis) & 6.0 \\
\hline 2025 (prognosis) & 8.4 \\
\hline
\end{tabular}


However, if we look at these data globally, it will be evident that \$ 3.6 billion of exports of IT services to Ukraine in 2017 is a "drop in the sea", compared to the global IT industry market of 3.5 trillion dollars (in the same year).

Global IT Services Market in 2015-2019

Table 2

Global exports of IT products and services [45]

\begin{tabular}{|c|c|}
\hline Year & Market volume (trillion dollars) \\
\hline 2015 & 3.5 \\
\hline 2016 & 3.4 \\
\hline 2017 & 3.6 \\
\hline 2018 & 3.7 \\
\hline 2019 & 3.8 \\
\hline
\end{tabular}

In 2018, the growth of the IT market has increased to $30 \%$. If the current growth rate is maintained after 5 years, information technologies have every chance to become second in the structure of Ukrainian exports. Last year, Ukraine's IT sector continued to grow at a faster pace than the country's economy as a whole. Tax revenues from the IT sector to the state budget in 2018 increased by $38 \%$ to $\$ 300$ million. Information technologies confidently occupy the third position in terms of export revenues, second only to agribusiness and metallurgy ${ }^{19}$.

The information technology sector can grow to $\$ 8.4$ billion by 2025 . The IT sector is already a key driver in the Ukrainian economy and shows the largest growth among other export industries. This growth has been achieved thanks to the young generation of engineers - in the last four years the number of IT specialists has increased from 42.4 thousand to 91.7 thousand. Although the IT industry in Ukraine occupies a small share of the global IT services market, it is constantly developing at a rapid pace.

The capital of Ukraine, Kyiv, is an attractive tourist destination due to its historical sites, churches, castles, museums and gardens. But the city is also an important educational and technological center in Eastern Europe. In the 2017 Startup Blink report, Kyiv ranks first in Ukraine and 63-rd worldwide ${ }^{20}$.

According to the Kyiv Post, the Ukrainian IT industry is worth more than $\$ 5$ billion, with more than 500 outsourcing companies, 50.000 engineers and 100 global R\&D centers.

19 URL: https://www.n-ix.com/kyiv-developers-exploring-biggest-hub-ukraine/.

20 URL: https://www.n-ix.com/kyiv-developers-exploring-biggest-hub-ukraine/. 
What is the secret to the success of startups in Ukraine? There are a number of reasons for this, which lead to a competitive advantage in creating and promoting IT startups.

1. A lot of IT talent. Ukraine ranks third in the 50 countries with the most certified IT professionals, behind the US and India. Thousands of highly qualified specialists annually graduate from universities. No wonder giants such as Samsung have set up research and development centers in Ukraine. Interesting fact: one of the founders of WhatsApp, Jan Kum, is a Ukrainian. Ukraine also ranks third when it comes to freelancers. Moreover, wages are much lower here than in other parts of Europe and the US.

2. Low cost of living. The low cost of living makes Ukraine an ideal place for startups.

3. Events and conferences. Ukraine also hosts a large number of international conferences and forums that bring together IT entrepreneurs and innovators from around the world. Some of these conferences include iForum, Seed Forum, IDCEE and Startup AddVenture, which are attended by professionals and investors from around the world.

\section{CONCLUSIONS}

What are the implications of Industry 4.0 for MNEs and international business theory? First and foremost, the emergence of new institutional arrangements will clearly impact upon the activities and strategic decisions of MNEs, and this would be a fertile area for future research. Furthermore, research might also consider the following questions, grouped according to the familiar framework of the eclectic paradigm (Dunning, 1977, 2000) and couched in terms of ownership, location and internalization (OLI) advantages.

What will constitute important ownership (firm-specific) advantages under Industry 4.0? What value chain activities will MNEs need to control, and what isolating mechanisms will they need to possess (Rumelt, 1984; Rumelt, 1987; Lawson et al., 2012) for them to capture the rents earned in GVCs? If manufacturing activities are carried outby a combination of publicly available robotic systems and independent 3-D printing supercentres, then will the ownership of production capacity allow effective value capture, or can such activities be outsourced? Will it become more important for MNEs to control the design and distribution stages of GVCs? But 3-D printing will potentially allow customers to have greater input in the design of their products, and control over where and when it is manufactured. Or will BDA adoption allow large firms to anticipate market trends and to offer customer 
benefits that are hard for competitors to imitate? Will formal property rights allocated by the State (e.g. patents, trademarks, licenses) or brand names and/or corporate reputations be effective isolating mechanisms in a world of product customization and dispersed manufacturing?

What will be the nature of location advantages under Industry 4.0? International business is based on a concept of geography that may be partially challenged in an Industry 4.0 scenario (Gress and Kalafsky, 2015). Clearly, greater use of robotic systems will minimize the cost economies that are realized from locating manufacturing activities in low laborcost countries, such as the emerging economies. But will this mean that such activities are reshored to traditional (advanced economy) locations? If so, what will be the impact upon employment opportunities (Frey and Osborne, 2017) given the capital-intensive nature of the manufacturing process? Or will manufacturing activities increasingly be located closer to the final customers? Certainly this would be the logical conclusion from the widespread adoption of 3-D printing. These developments will have significant impacts upon what products are traded, what is exported from where and imported to where, and where jobs are sustained. The spread of additive manufacturing would reduce trade in finished goods, and local availability of the necessary raw materials would also reduce trade in intermediate goods. How will host and home country governments react, and what policies will they enact to promote/restrict trade and FDI?

Finally, what internalization advantages will be critical under Industry 4.0? Are there advantages to being vertically-integrated in the face of the technological changes identified above ${ }^{21}$ (Langlois, 2003) and, if so, what should be internalized and what should be externalized? Should knowledge (including big data) be increasingly internalized within MNEs, whilst operations are increasingly externalized? Certainly it appears that the key capabilities that will guide firm performance in the future will be those that address, on the one hand, the need to anticipate and shape future customer demands and, on the other hand, the need to bring about greater efficiencies in the distribution of final goods. These capabilities are inextricably linked to the deployment of BDA and the IoT, and it will be firms that can afford to invest in these nascent digital technologies and employ the associated high-skilled skilled labor that will flourish. This is the future of the MNE in the coming decades of the twenty-first century.

21 Afuah A. Dynamic boundaries of the firm: are firms better off being vertically integrated in the face of a technological change? Academy of Management Journal, 2001, Vol. 44. No. 6, pp. 1211-1228. 


\section{SUMMARY}

This article is an assessment of how widespread adoption of new digital technologies (Industry 4.0) might affect the location and organization of activities within global-value chains (GVCs) revealing that digital technologies have considerable potential to disrupt how and where activities are located and organized within GVCs. This paper aims to provide an assessment of how the widespread adoption of new digital technologies (i.e. the Internet of things, big data and analytics, robotic systems and additive manufacturing) might affect the location and organization of activities within global value chains (GVCs). Many scientific papers devoted to global value chains (GVCs) challenges, are focused on establishment of spatial relations by global companies while creating added value from localization of manufacturing and trade and financial transactions primarily nationwide. Digital Transformation as the integration of digital technology into all areas of a business resulting in fundamental changes to how businesses operate and how they deliver value to customers. The rise of cloud computing, big data, Internet of Things (IoT), and artificial intelligence (AI) are driving a digital and intelligent transformation of enterprises. With the in-depth integration of IT and enterprises, profound changes will take place in the production method, enterprise organization, product mode, and service mode of the industry. IT products and services in Ukraine, together with IT specialists, are known worldwide. Despite all the obstacles, Ukraine holds key positions in virtually all indicators in this sector.

\section{REFERENCES}

1. Tihinen M., Kääriäinen J. (eds.). The Industrial Internet in Finland: on route to success? Espoo, Finland: VTT, VTT Technology; 278. ISBN 978-95138-8484-0, URL: http://www.vtt.fi/inf/pdf/technology/2016/T278.pdf, 2016.

2. Degryse C. Digitalisation of the economy and its impact on labor markets, Working paper 2016.02, Published by the European Trade Union Institute (ETUI), 2016.

3. The Economist. The third industrial revolution. 2012. URL: http://www.economist.com/node/21553017.

4. Schwab K. The Fourth Industrial Revolution (Foreign Affairs). 2015, Dec, 12. URL: https://www.foreignaffairs.com/articles/2015-12-12/ fourth-industrial-revolution.

5. Tihinen M., Iivari M., Ailisto H., Komi M., Kääriäinen J. and Peltomaa I. An exploratory method to clarify business potential in the context of industrial internet - a case study, in Collaboration in a Hyperconnected World, 17th IFIP 
WG 5.5 Working Conference on Virtual Enterprises, PRO-VE 2016, Hamideh, Afsarmanesh et al., eds. Springer, Porto, Portugal. 2016. Pp. 469-478.

6. Stolterman E., Fors A. Information Technology and the Good Life in Information Systems Research: Relevant Theory and Informed Practice / B. Kaplan et al. (eds), London, UK : Kluwer Academic Publishers, 2004.

7. Gassmann O., Frankenberger K. and Csik M. The St. Gallen Business Model Navigator. 2014. URL: http://www.im.ethz.ch/education/HS13/MIS13/ Business_Model_Navigator.pdf.

8. Henriette E., Mondher F. and Boughzala I. The Shape of Digital Transformation: A Systematic Literature Review, in Ninth Mediterranean Conference on Information Systems (MCIS), Samos, Greece, 2015.

9. Brennen S. and Kreiss D. Digitalization and Digitization. 2014. URL: http://culturedigitally.org/2014/09/digitalization-and-digitization/.

10. Markovitch S. and Willmott P. Accelerating the digitization of business processes. White paper, McKinsey \& Company. 2014. URL: http://www.mckinsey.com/insights/business_technology/accelerating_the digitization_of_business_processes.

11. Sabbagh K., Friedrich R., El-Darwiche B., Singh M., Ganediwalla S. and Katz R. Maximizing the impact of digitization (Strategy\&). Previously published in the Global Information Technology Report 2012: Living in a Hyperconnected World, pwc, pp. 68-73, 2012. URL: http://www.strategyand. pwc.com/media/file/Strategyand_Maximizing-the-Impact-of-Digitization.pdf.

12. Kane G.C., Palmer D., Phillips A.N., Kiron D. and Buckley N. Strategy, not Technology, Drives Digital Transformation, Becoming a digitally mature enterprise. MIT Sloan Management Review, 2015. URL: http://sloanreview.mit. edu/projects/strategy-drives-digital-transformation/.

13. Afuah A. Dynamic boundaries of the firm: are firms better off being vertically integrated in the face of a technological change? Academy of Management Journal, 2001, Vol. 44. No. 6, pp. 1211-1228.

14. The Rise of Robotics. BCG article, August 2014.

15. Prepare for Impact: 3-D Printing Will Change the Game. $B C G$ article, September 2013.

16. The Shifting Economics of Global Manufacturing: How Cost Competitiveness Is Changing. World-wide, $B C G$ report, August 2014.

17. Made in America, Again: Why Manufacturing Will Return to the U.S., $B C G$ Focus, August 2011.

18. Albertoni F., Elia S., Fratocchi L. and Piscitello L. Returning from offshore: what do we know?, AIB Insights, 2015. Vol. 15. No. 4, pp. 9-12.

19. Baum C. and Wee D. Manufacturing's Next Act, McKinsey \& Company. 2015.

20. O’Reilly. Big Data Now: 2012 edition, Sebastopol, CA: O’Reilly Media. 
21. IDC Digital Universe Study: Extracting Value from Chaos. 2011. URL: http://www.emc.com/collateral/analyst-reports/idc-extracting-valuefromchaos-ar.pdf (Last accessed: 11.05.2014).

22. Schmarzo B. Big Data: Understanding how data powers big business, Indianapolis, IN : John Wiley \& Sons. (2013.

23. Varian H.R. Computer Mediated Transactions. American Economic Review. 2010. No 100(2). Pp. 1-10.

24. Porter T.M. Trust in Numbers: The pursuit of objectivity in science and public life. 1995. New Jersey : Princeton University Press.

25. Desrosières A. The Politics of Large Number: A history of statistical reasoning. 1998. Cambridge, MA : Harvard University Press.

26. Bowker G.C. and Star S.L. Sorting Things Out: Classification and its consequences, inside technology. 1999. Cambridge, MA : The MIT Press.

27. Rosenfeld 1. and Morville P. Information Architecture for the World Wide Web. 2002, Sebastopol, CA : O'Reilly Media.

28. Weinberger D. Everything is Miscellaneous: The power of the new digital disorder. 2007. New York : Times Books.

29. Beniger J.R. The Control Revolution: Technological and economic origins of the information society. 1986. Cambridge, MA: Harvard University Press.

30. Chen H., Chiang R.H. and Storey V.C. Business Intelligence and Analytics: From big data to big impact. 2012. MIS Quarterly 36(4). Pp. 1165-1188.

31. Ekbia H. and Evans T. Regimes of Information: Land use, management, land policy. The Information Society. 2009. No 25(5). Pp. 328-343.

32. Bhimani A. and Willcocks L. Digitisation, "Big Data" and the Transformation of Accounting Information. Accounting and Business Research. 2014. No 44(4). Pp. 1-22.

33. Bowker G.C. Memory Practices in Sciences. 2005. Cambridge, MA: The MIT Press.

34. Morville P. Ambient Findability. 2005. Sebastopol, CA: O'Reilly Media.

35. Borgmann A. Holding on to Reality: The nature of information at the turn of the millennium. 1999. Chicago : The University of Chicago Press.

36. Eco U. Kant and the Platypus: On language and cognition. 2000. London : Vintage.

37. Manovich L. The Language of New Media. 2001. Cambridge, MA : The MIT Press.

38. Kallinikos J. and Mariategui J.-C. Video as Digital Object: Production and distribution of video content in the Internet media ecosystem. 2011. The Information Society. No 27(5). Pp. 281-294. 
39. Adelman C. A Parallel Post-secondary Universe: The Certification System in Information Technology. 2015. Washington, D.C.: Міністерство освіти США.

40. Allen T., and Morton M.S. (eds.). Information Technology and the Corporation of the 1990s. 1994. New York : Oxford University Press.

41. Shelly Gary, Cashman Thomas, Vermaat Misty, and Walker Tim. Discovering Computers 2000: Concepts for a Connected World. 2013. Cambridge, Massachusetts : Course Technology.

42. Webster Frank, and Robins Kevin. Information Technology - A Luddite Analysis. 2011. Norwood, NJ : Ablex.

43. URL:

https://www.sourceseek.com/ reflections-from-outsource-people-2015-in-kyiv/.

44. URL: https://itcluster.kiev.ua/.

45. URL: http://communities.techstars.com/ukraine/kiev

46. URL: http://startupkyiv.com/.

47. Wang Shan X.; Taratorin A.M. Magnetic Information Storage Technology, Academic Press, 1999. ISBN 978-0-12-734570-3.

48. URL: https://www.n-ix.com/kyiv-developers-exploring-biggest-hubukraine/.

Information about author: Karmaza O. O., ORCID: 0000-0003-4895-5220 D.Sc. (Law), Professor, Professor at the Institute of Continuing Education Taras Shevchenko National University of Kyiv Vasylkivska Street, 36, Kyiv, Ukraine

DOI https://doi.org/10.30525/978-9934-588-43-3/2.6 